\title{
LEGITIMIDAD Y JUSTICIA: LA CONSTITUCIÓN, ZONA DE MEDIACIÓN
}

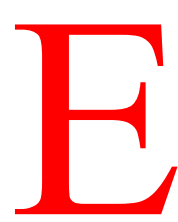

$\mathrm{n}$ estas muy breves páginas se intenta dar un paso adelante (no decisivo, 1o admito, pero tal vez tampoco del todo inútil) en relación con algunas propuestas conclusivas formuladas, en trabajos míos anteriores y, en concreto, en el último sobre La justificación de la democracia ${ }^{1}$.

Entre otras cosas, se trataba en él de establecer algunos criterios válidos para poder hablar con alguna mayor claridad y coherencia de una teoría de la legitimidad (democrática) y de una correlativa teoría (crítica) de la justicia. La zona, compleja e inestable, de convergencia entre ambas dimensiones se identificaba allí haciéndola derivar del valor libertad, entendida ésta en su punto (básico) de partida como libertad crítica, de expresión y de participación. La libertad venía así configurada como el valor fundamental tanto para la legitimidad democrática (preferentemente, aunque no sólo, procedimental) como para una, en su totalidad siempre inalcanzada y quizás inalcanzable, justicia material. Las mayorías -se recalcaba en aquellas páginas con insistencia- pueden equivocarse; es decir, la legitimidad democrática puede producir cosas injustas. Legitimidad y justicia no eran, no son exactamente lo mismo, aunque por supuesto que tienen mucho que ver entre sí.

Pero ¿qué es preferible si hay conflicto? ¿Respetar la regla procedimental, la libre decisión, o sea respetar la democracia (en ese su aspecto principal aunque no único) y hasta la soberanía popular o imponer por vías antidemocráticas lo que alguien considera justo? La complejidad del dilema se muestra ya con la mera formulación del interrogante: ¿Qué seria preferible: hacer «injusticias» democráticamente (por ejemplo, permitir el aborto dirán unos, reimplantar la pena de muerte, señalarán otros o los mismos) o hacer «justicia» (permitir o reimplantar esas mismas cosas) a la fuerza, sin democracia, sin libertad? En este tipo de cuestiones andaban esas mis anteriores elucubraciones con preferencia clara por la regla de decisión de carácter democrático, en libertad, completada por la intervención de un diseño de teoría de la justicia donde las «necesidades reales» («necesidades básicas» y algo más que básicas), la razón crítica personal, la conciencia ética de la humanidad y hasta la «comunidad ideal de diálogo» se alegaban, sin entrar allí más a fondo, como componentes centrales de aquélla.

${ }^{1}$ Publicado en la revista «Sistema» (núm. 66, mayo de 1985, págs. 3-23). Dicho trabajo prolongaba a su vez, e intentaba aclarar, cuestiones planteadas en mi anterior libro De la maldad estatal y la soberanía popular, Madrid, Debate, 1984. 
La libertad, pues, venía aludida -desde esa perspectiva más bien de principios y hasta abstracta- como el punto de convergencia entre precisamente una teoría de la legitimidad (democrática) y una teoría (crítica) de la justicia; y, por tanto, asimismo (puede decirse en términos aún más genéricos) como posible zona de encuentro entre las denominadas legitimidad procedimental y justicia material. Pero me parece que de esa regla interpretativa en favor de la libertad (de todos modos en absoluto por sí misma inoperante, más bien todo lo contrario) derivan y pueden derivar conclusiones mucho más concretas, tal vez por ello también más convincentes, a la hora de determinar con mayor detalle y precisión dicha zona válida de no definitiva mediación. De algo de eso es de lo que brevemente quería ocuparme aquí.

La libertad (la libertad positiva) ejerciéndose libremente, valga la aparente redundancia, se actúa a través de la soberanía popular, la cual cuando se trata de salir de la (o de una) posición originaria (o relativamente originaria) se muestra en sus caracteres básicos como poder constituyente. De este modo, la Constitución, el gran pacto social constitucional, sintetiza así, puede decirse -sobre todo cuando es producto del consenso entre partes plurales y resulta aprobada por muy amplias mayorías-, ese espacio de convergencia entre legitimidad democrática y justicia material (una cierta justicia material), cuya caracterización y difícil clarificación viene reclamándose como cuestión central de la filosofía jurídico-política y ética de nuestro tiempo (y quizás de todos los tiempos).

La Constitución, creada en esas condiciones, es expresión por de pronto de la legitimidad democrática, entendida como mínimo, como legitimidad procedimental. Expresa, primeramente también a través del consenso, la voluntad libre de las grandes mayorías del grupo social. Esta concepción democrática de la Constitución, y del Derecho en general, se diferencia pues con toda claridad tanto de la concepción exclusivamente consensualista (o corporativista, sin ser tampoco estas dos lo mismo) como de la de estricto carácter iusnaturalista. Respecto al Derecho y, más en concreto, respecto a la Constitución así creada, por supuesto -pero éste es otro tema- que quien disienta seriamente en conciencia puede dar razones éticas para desobedecerla, en todo -como juicio global- o en la parte que resulte afectada. No hay que volver a insistir aquí en que puede haber razones éticas (y hasta obligación moral) para desobedecer al Derecho; pero, a su vez, puede haberlas también, en mi opinión -ya sé que en esto cuento con ilustres discrepantes-, para obedecerlo ${ }^{2}$.

\footnotetext{
${ }^{2}$ Sobre ello, además de la bibliografía ya citada y discutida en los escritos aludidos en la nota precedente, puede verse el muy documentado libro de EUSEBIO FERNÁNDEZ GARCÍA, $L a$ obediencia al Derecho, Madrid, Civitas, 1987: de manera muy especial, págs. 91 a 115 para una reciente polémica en la filosofía jurídica yética española actual sobre la obligación moral de obedecer al Derecho (también Eusebio Fernández piensa que puede haberla); y págs. 157 y ss. para la explicación y fundamentación de las razonables actitudes del autor sobre tan complejos y debatidos problemas; por
} 
No voy a entrar ahora de nuevo en esta discusión, vieja polémica donde las haya. Lo que me interesaba resaltar aquí en esta línea argumental es que la Constitución, y antes el poder constituyente, sintetizan y expresan la denominada justicia procedimental, la que -dando un paso más- puede designarse como legitimidad de carácter democrático. Esto es pacífico y no suscita, desde luego, mayores discrepancias (excepto, claro está, para los antidemócratas). Otra cosa muy diferente es, sin embargo, el grado de justicia material que quepa atribuir a tal democrática Constitución. Seguro que ni siquiera los sectores que la han consensuado y votado (las grandes mayorías, supongamos) la consideran del todo justa en unas u otras decisiones y, menos aún, justa en su totalidad (justas todas sus decisiones). Pero seguro también que, en líneas generales y en no pocas cuestiones concretas, aquellos reconocerán que contiene con bastante coherencia lo que ese grupo social, o esas grandes mayorías, consideran como suficiente, adecuadamente justo, es decir como justicia material en cuanto justicia histórica concreta o concreción histórica de la justicia material. Si todos han podido hablar, contraponiendo libre y abiertamente sus juicios y razonamientos éticos -como debe ser en democracia-, entonces esa «justicia material», a pesar de todas las posibles distorsiones y manipulaciones, cabe decir que expresa y representa algo muy atendible, algo con relativa -no definitiva- consistencia también desde el punto de vista de la objetividad y hasta de la verdad.

Quiero decir, en consecuencia, con todo ello que la Constitución y el poder constituyente son y pueden verse en esta perspectiva como zona de mediación y de convergencia de una suficiente (siempre imperfecta, nunca estática e inmutable) legitimidad democrática $\mathrm{y}$, a su vez (aquí con aun mayores imperfecciones y variaciones), de una objetiva justicia material (histórico-material) en todo caso sometida, por supuesto, a pertinentes críticas y a racionales contrastaciones. Esa legalidad constitucional, no cualquier legalidad (que «algo» puede representar también), sino esa de carácter fundamental constitucional, es así punto de encuentro de la legitimación social, la legitimidad democrática y la (relativa, histórica) justicia material. Me parece importante esa zona de convergencia formada por el poder constituyente, la Constitución y los grandes pactos políticos sociales. Si después de ello, si después, sobre todo, de la Constitución las decisiones legales mayoritarias van contra ella (contra esa legitimidad y esa justicia) sencillamente tales decisiones quedan anuladas al probarse su anticonstitucionalidad por el pertinente Tribunal. Esas mayorías concretas, por lo tanto, aunque «enloquezcan»

el momento yo únicamente objetaría, preguntaría más bien, lo siguiente ante sus matizadas objeciones a mi, tal vez, más objetivista posición (págs. 101 a 104): ¿el deber moral sólo es lo que uno siente como deber moral?; ¿no hay obligación moral de respetar la vida de los demás para el asesino que no siente, en general o en un caso concreto, esa obligación?; ¿no hay obligación moral para el dictador -aunque de hecho él no la sienta así, aunque fácticamente no la haya para él-, no se le puede justificar la obligación moral de respetar la libertad y la dignidad de sus conciudadanos, degradados así a meros súbditos? Por supuesto que -como aduce Eusebio Fernández- estoy manejando aquí dos conceptos diferentes de obligación moral, la fáctica-empírica y ética-racional; pero me parece necesario hacerlo. 
-cosa que alegan incansablemente los antidemócratas- no podrán hacer nada, por vías legales y democráticas, contra la Constitución. La posible reforma de ésta, por su parte, nos devuelve a la ya referida situación de la posición originaria, donde el poder constituyente si quiere ser democrático no puede violar el valor material y procedimental de la libertad, de al menos una cierta libertad, de expresión, de crítica, de participación en la elección, etc. ${ }^{3}$.

Tanto la regla procedimental como la justicia material son, pues, expresión de la libertad; y ambas, a su vez, están incorporadas en la Constitución como norma básica o principio determinante de ella ${ }^{4}$. La justicia material de la Constitución que, en mi opinión, incluye la regla genérica procedimental (es decir, los valores superiores incluyen la libertad democrática), constituye un límite objetivo insalvable -y así debe ser- para la decisión procedimental de mayorías que no se adapten en sus decisiones jurídicas y políticas a la norma constitucional; repito que otra cosa, y también con límites, son los supuestos de reforma. Esa referencia, ese necesario respeto, a la Constitución evita, pues, los «peligros» de que en el sistema político basado en la libertad, en las decisiones libres de los ciudadanos, se puedan producir cualquier tipo de monstruosidades, de injusticias, de locuras, quedando todo a merced de la voluble voluntad de unas simples mayorías actuando incondicionada e irresponsablemente, cosa que -como digo- tan propensos son siempre a alegar los antidemócratas que, sin embargo, para nada se alarman de dichas monstruosidades e injusticias cuando son producidas por regímenes oligárquicos y dictatoriales. La justicia material de la norma fundamental, la Constitución sin más (que incluye necesarios equilibrios, consensos realistas y presencia de minorías que pueden llegar un día a ser mayorías), garantiza ya un cierto, importante nivel de comportamiento ético, una vía bastante sólida hacia los objetivos últimos de una teoría crítica de la justicia.

Un concepto de «legitimidad» muy cercano a éste es -creo- el que utiliza Ernesto Garzón Valdés -en este número de «Doxa» tan justamente homenajeado-, en un reciente y valioso trabajo sobre la estabilidad política, al vincular aquélla (la legitimidad) a -dice- «la concepción usual de los derechos humanos tal y como han sido formulados, por ejemplo, en la Declaración Universal de las Naciones Unidas». Y también él orientaría esa legitimidad hacia un juicio ético normativo (teoría de la justicia) más objetivo y hasta más definitivo, cuando señala que dicho juicio «toma como criterio para su formulación la vigencia de normas

${ }^{3}$ Cfr. sobre ello la importante obra de PEDRO DE VEGA, La reforma constitucional y la problemática del poder constituyente, Madrid, Tecnos, 1985.

${ }^{4}$ Reenvío aquí a la nota 10 de mi mencionado trabajo sobre La justificación de la democracia donde, en relación con los escritos de los profesores Laporta y Peces Barba, se especificaban asimismo en cuanto norma básica de nuestra Constitución esos dos principios de la soberanía popular (art. 1,2) como «regla procedimental» y de los valores superiores de ella (art. 1,1) como «justicia material». 
éticas aceptables por todo aquel que esté dispuesto a admitir la autonomía personal de cada individuo y su igualdad básica con respecto al acceso y goce de aquellos bienes que, usando la terminología de John Rawls, pueden ser denominados «bienes primarios», es decir, aquellos sin los cuales no es posible la realización de ningún plan de vida $»^{5}$.

Pero por supuesto que algo que figura en la Constitución puede ser considerado como injusto, o puede serlo efectivamente, aunque esto último no siempre sea fácil de determinar y de objetivar; y desde luego que algo no es justo por el mero hecho de que figure en la Constitución. La legalidad constitucional no se confunde nunca del todo, aunque pueda tener estrecha relación con la legitimidad (democrática), la cual es siempre, por su propio carácter, más dinámica y exigente; y, sobre todo, en modo alguno esa legalidad y esa justicia material inserta en ella pueden pretender identificarse, por ese mero hecho, con lo que objetivamente puede calificarse de justo. Pero lo que sí mantendría es que la Constitución democrática, la legitimidad que la origina, con libertad y con autonomía moral, y la justicia material en que aquélla se reconoce son, en principio, las mejores vías para construir una teoría ética y una teoría crítica de la justicia. La efectiva satisfacción para todos de amplias necesidades básicas, la regla de la libertad, el establecimiento de límites precisos a ciertas desigualdades, el derecho a la diferencia, el libre diálogo crítico, y los derechos que se derivan de ahí, son asimismo algunas otras exigencias fundamentales imprescindibles hoy para avanzar hacia esa ética, hacia esa teoría crítica de la justicia. En definitiva, ésta (la justicia) tal vez pueda ser entendida finalmente como la inteligente (coherente) articulación de todos estos elementos, y algunos más, para el análisis concreto de las situaciones concretas y la progresiva transformación de las que no se correspondan de manera suficiente con esos valores y objetivos derivados fundamentalmente de la libertad.

${ }^{5}$ ERNESTO GARZÓN VALDÉS, El concepto de estabilidad de los sistemas politicos, Madrid, Centro de Estudios Constitucionales, 1987, pág. 45. Aparte de esto, preguntaría yo a Ernesto Garzón Valdés, en otra vertiente del problema (pág. 46 y ss.), si no sería oportuno que su modelo analítico combinatorio de tres dígitos (símbolos respectivamente de la existencia fáctica, legitimidad y estabilidad de los sistemas políticos, que lo serían así de orden 111, 110, 101 y 100), se completase pasando a considerar también una cuarta variable, segunda dentro de su esquema, precisamente la «legitimación» (como «aceptación» del sistema, pág. 7) en la medida en que, aún próxima, no puede confundirse tal categoría con la mera existencia fáctica de un régimen político que, en efecto, puede en tiempo ir perdiendo o ganando legitimación: tendríamos, así, Sistemas más complejos, de cuatro elementos, representados como 1000, 1010, 1011, 1100, 1101 y 1111 correlativamente, que enriquecerían -me parece- el análisis de los concretos regímenes políticos existentes. La dimensión de la legitimación o deslegitimación es también un ingrediente que afecta a la misma legitimidad y desde luego que, aunque no se identifica del todo con ella, tiene mucho que ver con la estabilidad.

\section{DOXA 4 (1987)}

